\title{
Modification of Clay Crystal Structure with Different Alcohols
}

\author{
M. Ozgur Seydibeyoglu1 ${ }^{*}$, Sibel Demiroglu², Metehan Atagur ${ }^{1}$, Selmin Yanar Ocaktan ${ }^{3}$ \\ ${ }^{1}$ Department of Materials Science and Engineering, Izmir Katip Celebi University, Izmir, Turkey \\ ${ }^{2}$ Nanotechnology Graduate Program, Izmir Katip Celebi University, Izmir, Turkey \\ ${ }^{3}$ DYO Paint Company, Izmir, Turkey \\ Email: *seydibey@gmail.com
}

How to cite this paper: Seydibeyoglu, M.O., Demiroglu, S., Atagur, M. and Ocaktan, S.Y. (2017) Modification of Clay Crystal Structure with Different Alcohols. Natural Resources, 8, 709-715. https://doi.org/10.4236/nr.2017.811044

Received: September 8, 2017

Accepted: November 27, 2017

Published: November 30, 2017

Copyright (c) 2017 by authors and Scientific Research Publishing Inc. This work is licensed under the Creative Commons Attribution International License (CC BY 4.0).

http://creativecommons.org/licenses/by/4.0/

\begin{abstract}
Clays attract attention as a nano size material to reinforce the polymers and resins. In this study, montmorillonite clay was modified using industrial solvents that are used in the paint industry. It was shown that the water contact angle could be varied from $20^{\circ}$ to $140^{\circ}$ which is a real influence for the clay mineral. X-ray diffraction analysis shows that planar basal space could be altered significantly from 12.57 to $15.40 \mathrm{~nm}$ showing $22.5 \%$ increase in the interlayer spacing and that is really critical for many polymers and coating applications. This study will highlight many new clay nanocomposites and the formation of various clay nanocomposites.
\end{abstract}

\section{Keywords}

Clay, Solvent, X-Ray Diffraction, Water Contact Angle

\section{Introduction}

Nanomaterials and nanotechnology have a big potential for many applications. Although there are many regulations regarding the nanomaterials for health issues, still there is a great investment in nanomaterials that can have commercial value. In the area of nanomaterials, nanoclays attracted great attention, as they are abundant in nature and readily available [1] [2] [3] [4] [5]. Moreover, Turkey has a great potential having good resources of clays [1].

Among many types of clays, montmorillonite (MMT) from the smectite family with a planar crystal structure has been the predominantly used clay for polymer reinforcement with intercalated and exfoliated structure in the polymer matrices [2]. MMT clays have been used for many different polymer systems but still not many commercial products have been obtained [2]. 
In this study, natural clay MMT was modified with different solvents that are used commercially in the coating industry. This is highly important to understand the interaction of the clay and the solvents to be able to use in the paint and coating industry. In this study, MMT was mixed with 6 different industrial solvents for various durations to understand the exfoliation behavior of the clay mineral. The water contact angle studies were also in depth study to understand the repellency and hydrophilicty/hydrophobicity of the clay after certain modifications.

This study demonstrates the importance of the solvents used to modify the clay microstructure opening many new dimensions for the clay research and clay based nanocomposites.

\section{Experimental}

\subsection{Materials and Methods}

\subsubsection{Materials}

Water based dye and 7 different kinds of alcohol (Etyldiglycol, Butylglycol, Dowanol, Isopropyl, Etylalcohol, Butyldiglycol, Isobutanol) were acquired from Dyo Paint Manufacturing and Trading Company Inc., Izmir, Turkey.

\subsubsection{Methods}

The nanoclay blend was formulated by adding the required weight of nanoclay to different types of alcohol at room temperature to obtain 10\% w/w blend and each blend was mixed at $300 \mathrm{rpm}$ by using multi-position digital stirring hotplates at room temperature. Mixing of blend was carried out at 60 and $180 \mathrm{mi}-$ nutes for each types of alcohol to achieve a homogeneous dispersion.

The final blends were poured into Petri dishes and left to stand overnight in an oven at $80^{\circ} \mathrm{C}$. After evaporation of the alcohols, the thin films were peeled off from Petri dishes and samples were characterization by using XRD (X-ray diffraction) and contact angle analysis. The X-ray diffraction analysis was carried out with Bruker D2 Phaser, X-ray diffract meter system with Ni filtered $\mathrm{CuK}_{\alpha}$ radiation $(\lambda=1.54 \AA$ ) generated at $45 \mathrm{kV}$ and $40 \mathrm{~mA}$. The diffracted X-ray beam was collected by scanning the detector between $2 \theta=1^{\circ}$ and $80^{\circ}$. The step size was $0.02^{\circ}$. Contact angle measurements were taken using a ThetaLite101, Biolin Scientific at ambient temperature. A liquid droplet of $3 \mu \mathrm{L}$ was deposited in to each sample surface using a testing syringe. The image of contact angle was obtained by a high-resolution digital camera and the contact angle results were based on 3 repeats.

\section{Results and Discussion}

\subsection{X-Ray Diffraction Analysis (XRD)}

The XRD patterns of the samples are shown in Figure 1. As shown in Figure $\mathrm{X}$ clearly indicates that the strong peak corresponding to the 001 montmorillonite mineral in the $2 \theta$ position is approximately 7 degree while, the interlayer spacing 


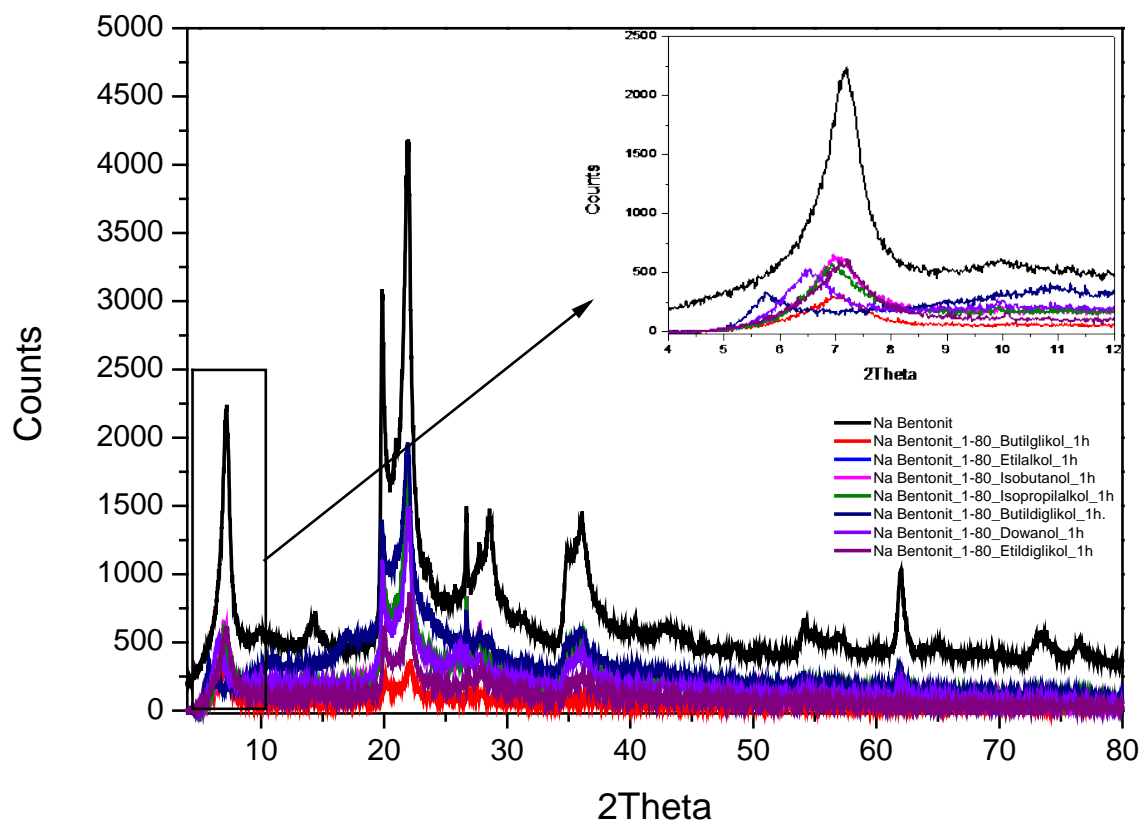

Figure 1. XRD patterns of samples of 1 hours mixing.

in the unmodified clay is approximately $12.41 \AA$. The other peaks are impurities corresponding to quartz and feldspar [6]. Mixing with different solvents leads to important mineralogical changes which can be seen from XRD patterns of samples (Figure 1 for $1 \mathrm{hr}$ mixing and Figure 2 for $3 \mathrm{~h}$ mixing). The most noticeable modification takes place in the montmorillonite $d$ (001) peak which shows a reduction in intensity as a result of mixing with various solvents. But, when comparing the results of $1 \mathrm{~h}$ and $3 \mathrm{~h}$ of mixing, significant differences were not observed between the intensity values.

As shown in Figure 1, during the mixing process, the organic compounds are placed between the clay layers, which results in the interlayer spacing increasing. The $\mathrm{d}(001)$ montmorillonite mineral peak displacements at $2 \theta$ is an appropriate criterion to evaluate the interlayer spacing. Specifically, a decrease in the $2 \theta$ angle indicates an increase in interlayer spacing [7]. The interlayer spacing values of the samples which were shown in Table 1, were obtained from XRD patterns.

As it can be understood from Table 1, interlayer spacing values was increased with the addition of all solvents both $1 \mathrm{~h}$ and $3 \mathrm{~h}$ mixing process. The maximum shifting value for interlayer spacing values of $\mathrm{Na}$ Bentonite was obtained by the addition of butyl diglycol $1 \mathrm{~h}$ and ethyl diglycol $3 \mathrm{~h}$. This increase may be a sign that the clay layers are separated and distributed more homogeneously in solution.

\subsection{Water Contact Angle Results}

Figure 3 indicates that the effect of clay-alcohol solution on the water contact, angle changed with mixing time. The contact angle results for the bottom and top surface are measured depending on different types of alcohol. The hydro- 


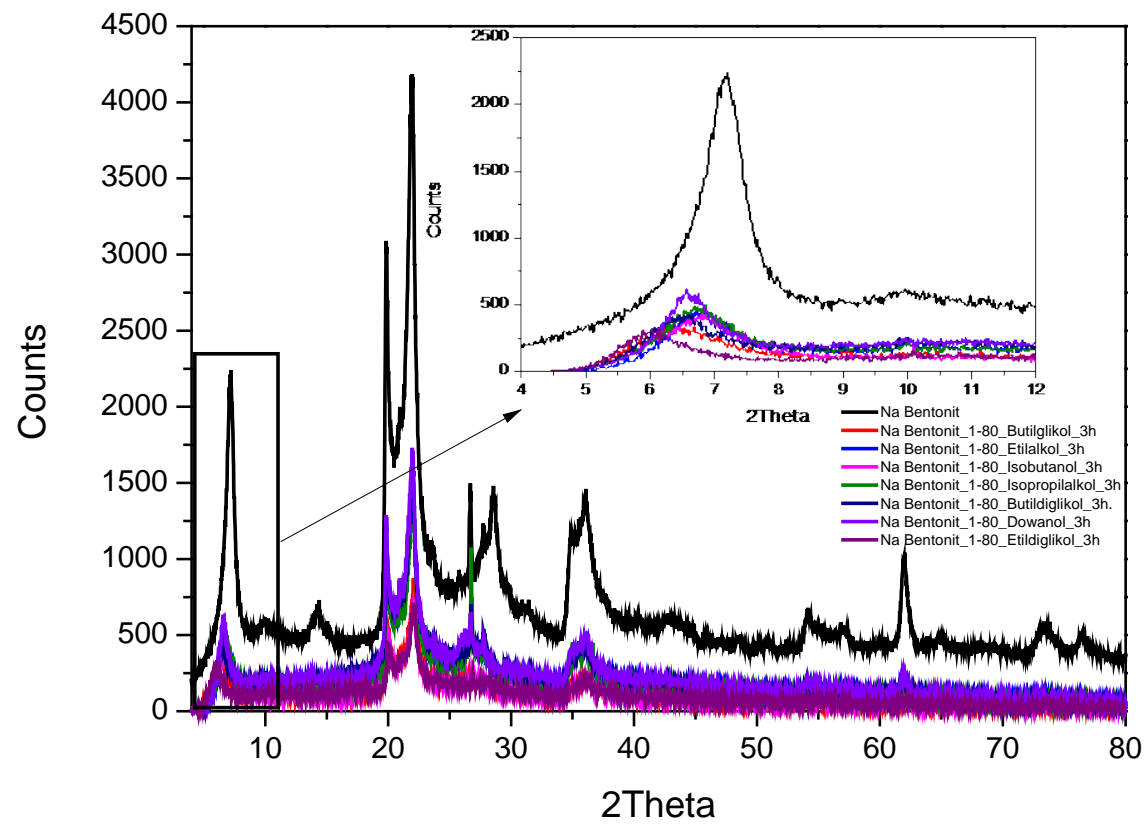

Figure 2. XRD patterns of samples of 3 hours mixing.

Table 1. Interlayer spacing values of the samples.

\begin{tabular}{ccc}
\hline Samples & \multicolumn{2}{c}{ Interlayer Spacing Values $(\AA)$} \\
\cline { 2 - 3 } & 1 h Mixing & 3 h Mixing \\
\hline Na Bentonite-Butyl glycol & 12.57 & 13.93 \\
Na Bentonite-ethyl alcohol & 12.67 & 13.16 \\
Na Bentonite-Isobutanol & 12.62 & 13.05 \\
Na Bentonite-Isopropyl alcohol & 12.78 & 13.22 \\
Na Bentonite-Butyl diglycol & 15.40 & 13.68 \\
Na Bentonite-Dowanol & 13.44 & 13.56 \\
Na Bentonite-Ethyl diglycol & 12.46 & 14.73 \\
\hline
\end{tabular}

philic nature of bentonite is attached to its polar interaction between bentonite and solvent [8] [9]. At the same time, when solution concentration is decreased, the water contact angle is decreased [10]. According to results of contact angle, with increasing molecular weight, the contact angle is based on the mixing time of solution.

The initial contact angles without mixing are seen for all samples and their behavior are still hydrophilic like bentonite. Also, the hydrophilicity is increased by increasing mixing time if larger molecular weight alcohols are used for preparing solutions. Figure 4 shows that the use of alcohol such as dowanol or ethyl diglycol decreased the contact angle and their behavior can be described super hydrophilic. On the contrary, the use of smaller alcohol like isopropyl alcohol tends to be hydrophobic behavior especially for $1 \mathrm{~h}$ mixing of solution. 


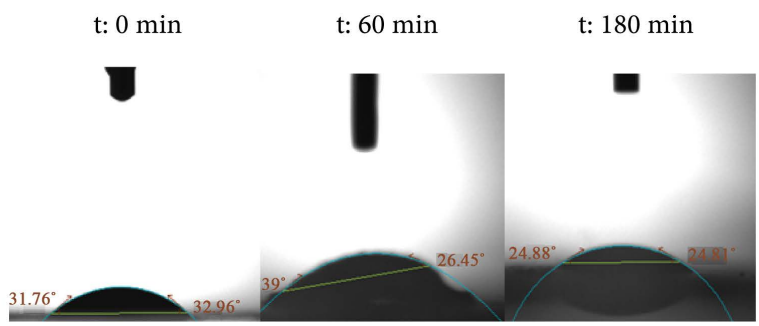

(a)

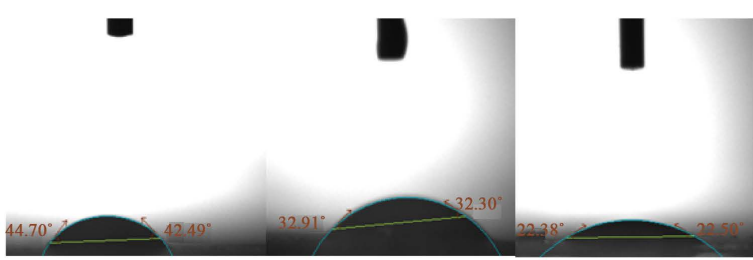

(b)

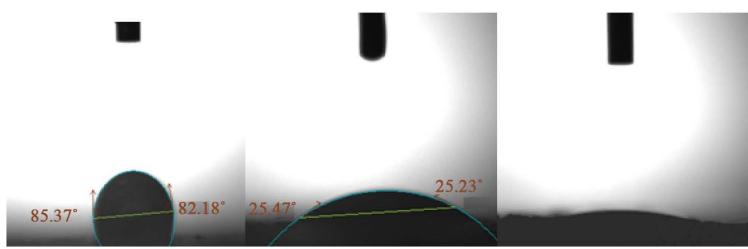

(c)

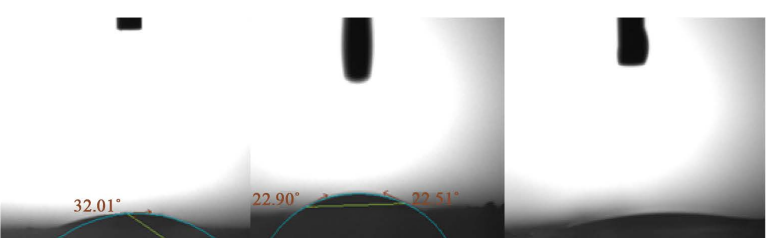

(d)

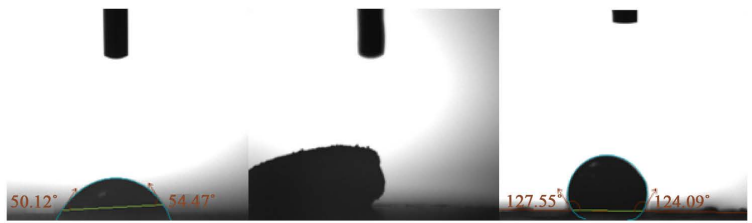

(e)

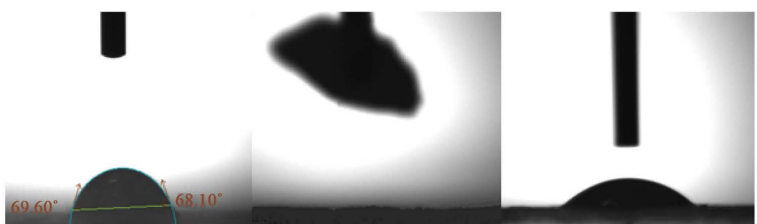

(f)

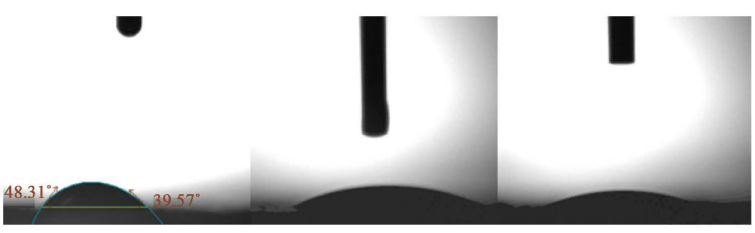

(g)

Figure 3. Images of the water contact angle of the (a) Ethyl alcohol; (b) Butyl glycol; (c) Ethyl diglycol; (d) Butyl diglycol; (e) Isobutanol; (f) Isopropyl; and (g) Dowanol polymeric surfaces at different mixing time: $0 \mathrm{~min}, 60 \mathrm{~min}$ and $180 \mathrm{~min}$. 


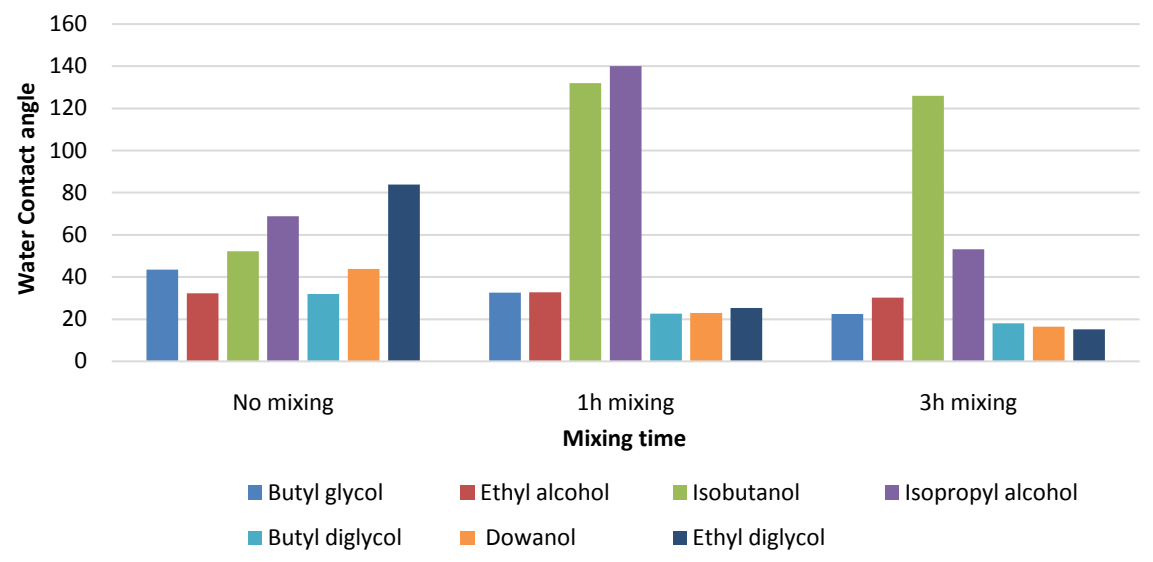

Figure 4. The water contact angles for Ethyl alcohol, Butyl glycol, Ethyl diglycol, Butyl diglycol, Isobutanol, Isopropyl, and Dowanol polymeric surfaces at different mixing time: $0 \mathrm{~min}, 60 \mathrm{~min}$ and $180 \mathrm{~min}$.

\section{Conclusion}

In this study, a detailed analysis of clays was done to understand the clay behavior with different solvents. It was shown that the clay material could be well exfoliated using suitable solvent for certain time. It is observed that water repellency of the clays could be well adjusted using different solvents. This study shows evidence to fine tune the clay structure for different applications including hydrophilic and hydrophobic nature.

\section{References}

[1] Seydibeyoğlu, M.Ö., Işçi, S., Ece, Ö.I., Güngör, N. and Güner, F.S. (2010) Preparation of Polyurethane/Hectorite, Polyurethane/Montmorillonite and Polyurethane/ Laponite Nanocomposites without Organic Modifiers. Journal of Applied Polymer Science, 116, 832-837.

[2] Ray, S.S. and Okamoto, M. (2003) Polymer/Layered Silicate Nanocomposites: A Review from Preparation to Processing. Progress in Polymer Science, 28, 1539-1641. https://doi.org/10.1016/j.progpolymsci.2003.08.002

[3] Solarski, S., Benali, S., Rochery, M., Devaux, E., Alexandre, M., Monteverde, F. and Dubois, P. (2005) Synthesis of a Polyurethane/Clay Nanocomposite Used as Coating: Interactions between the Counterions of Clay and the Isocyanate and Incidence on the Nanocomposite Structure. Journal of Applied Polymer Science, 95, 238. https://doi.org/10.1002/app.21254

[4] Choi, W.J., Kim, S.H., Kim, Y.J. and Kim, S.C. (2004) Synthesis of Chain-Extended Organifier and Properties of Polyurethane/Clay Nanocomposites. Polymer, 45, 6045-6057. https://doi.org/10.1016/j.polymer.2004.06.033

[5] Tortora, M., Gorrasi,G., Vittoria,V., Galli,G., Ritrovati, S. and Chiellini, E. (2002) Structural Characterization and Transport Properties of Organically Modified Montmorillonite/Polyurethane Nanocomposites. Polymer, 43, 6147-6157. https://doi.org/10.1016/S0032-3861(02)00556-6

[6] Zhirong, L., Azhar Uddin, M. and Zhanxue, S. (2011) FT-IR and XRD Analysis of Natural Na-Bentonite and $\mathrm{Cu}(\mathrm{II})$-Loaded Na-Bentonite. Spectrochimica Acta Part A: Molecular and Biomolecular Spectroscopy, 79, 1013-1016. https://doi.org/10.1016/j.saa.2011.04.013 
[7] Seo, K.S. and Kim, D.S. (2006) Curing Behavior and Structure of an Epoxy/Clay Nanocomposite System. Polymer Engineering \& Science, 46, 1318-1325. https://doi.org/10.1002/pen.20597

[8] Zheng, Y. and Zaoui, A. (2017) Wetting and Nanodroplet Contact Angle of the Clay 2:1 Surface: Thecase of Na-Montmorillonite (001). Applied Surface Science, 396, 717-722. https://doi.org/10.1016/j.apsusc.2016.11.015

[9] Jose, T., George, S.C., Maria, H.J., Wilson, R. and Thomas, S. (2014) Effect of Bentonite Clay on the Mechanical, Thermal, and Pervaporation Performance of the Poly (Vinyl Alcohol) Nanocomposite Membranes. Industrial \& Engineering Chemistry Research, 53, 16820-16831. https://doi.org/10.1021/ie502632p

[10] Jańczuk, B., Chibowski, E. and Białopiotrowicz, T. (1990) The Surface Free Energy Components of Homoion1c Bentonite from Contact Angle Measurements. Materials Chemistry and Physics, 26, 3-4. https://doi.org/10.1016/0254-0584(90)90025-6 